\title{
Erratum to: Production of an oligosaccharide-specific cellobiohydrolase from the thermophilic fungus Thielavia terrestris
}

\author{
James Sy-Keen Woon • Mukram Mohamed Mackeen • Amirul Husna bin Sudin • \\ Nor Muhammad Mahadi • Rosli Md Illias • Abdul Munir Abdul Murad • \\ Farah Diba Abu Bakar
}

Published online: 25 February 2016

(C) Springer Science+Business Media Dordrecht 2016

\section{Erratum to: Biotechnol Lett DOI 10.1007/s10529-016-2045-z}

Unfortunately, Author name "Mukram Mohamed Mackeen" had been published incorrectly as

The online version of the original article can be found under doi:10.1007/s10529-016-2045-z.

J. S.-K. Woon - A. M. A. Murad · F. D. A. Bakar ( $\square)$ School of Biosciences and Biotechnology, Faculty of Science and Technology, Universiti Kebangsaan Malaysia, 43600 UKM Bangi, Selangor, Malaysia e-mail: fabyff@ukm.edu.my

M. M. Mackeen · A. H. b. Sudin

School of Chemical Sciences and Food Technology, Faculty of Science and Technology, Universiti Kebangsaan Malaysia, 43600 UKM Bangi, Selangor, Malaysia

M. M. Mackeen · N. M. Mahadi Institute of Systems Biology (INBIOSIS), Universiti Kebangsaan Malaysia, 43600 UKM Bangi, Selangor, Malaysia
"Mukram MohamedMackeen" without a space. This error has been rectified in the original article.

N. M. Mahadi

Malaysia Genome Institute, Jalan Bangi Lama,

43000 Kajang, Selangor, Malaysia

R. M. Illias

Department of Bioprocess Engineering, Faculty of Chemical Engineering, Universiti Teknologi Malaysia, 81310 Skudai, Johor, Malaysia 